\title{
TRENDS OF CANCERS IN WOMEN - A RETROSPECTIVE STUDY IN AN INSTITUTE CATERING TO RURAL POPULATION
}

\author{
Gurneesh Singh', Karandeep Singh², Umesh Chhabra ${ }^{3}$, Alka Chhabra ${ }^{4}$
}

${ }^{1}$ Associate Professor, Department of Obstetrics and Gynaecology, Maharaja Agrasen Medical College, Agroha, Hisar, Haryana. 2 Professor and HOD, Department of Pathology, Maharaja Agrasen Medical College, Agroha, Hisar, Haryana.

${ }^{3}$ Associate Professor, Department of Surgery, Maharaja Agrasen Medical College, Agroha, Hisar, Haryana.

4 Senior Professor and HOD, Department of Obstetrics and Gynaecology, Maharaja Agrasen Medical College, Agroha, Hisar, Haryana.

\section{ABSTRACT}

\section{BACKGROUND}

Cancer is a major health burden worldwide. By 2030, over 9 million cancer patients are assumed to die in developing countries from different types of cancers.[1] Incidence of cancers in Indian women is increasing due to increased longevity, changing environmental factors, life style, late age of marriage, delayed pregnancies, obesity, etc.[2]

To determine the distribution pattern of different types of cancers in different age groups of women and compare it with National Cancer Registry, Delhi.

\section{MATERIALS AND METHODS}

A retrospective study was conducted from Jan. 2014 to May 2016. Records of female patients diagnosed with histologically proven female specific malignancies ( breast, uterus, ovary, cervix) were checked and data was analysed in terms of types of cancers, age related incidence ( $<20$ yrs., 20-30 yrs., 30-40 yrs., 40-50 yrs., 50-60 yrs., >60 yrs.). It was compared with National Cancer Registry data from Delhi.

\section{RESULTS}

There were total 118 female patients. Among all patients, breast cancer was the most common malignancy (39.05\%) followed by cervix (19.49\%), uterus (7.63\%), ovary (4.24\%) and others (24.58\%). Majority of cancers occurred in middle and older age groups.

\section{CONCLUSION}

The findings of the study show that breast cancer, cervical cancer, uterine cancer are more prevalent in rural areas of Haryana than Delhi and manifest early in younger age.

\section{KEYWORDS}

Breast Cancer, Cervical Cancer, Uterine Cancer, Ovarian Cancer, Trends, Distribution Pattern, Age Related Incidence.

HOW TO CITE THIS ARTICLE: Singh G, Singh K, Chhabra U, et al. Trends of cancers in women - A retrospective study in an institute catering to rural population. J. Evolution Med. Dent. Sci. 2016;5(86):6399-6402, DOI: 10.14260/Jemds/2016/1447

\section{BACKGROUND}

Cancer is a major health burden worldwide. An estimated 12.7 million new cancer cases occurred with 7.6 million deaths (around 13\% of all deaths) in 2008.[3] Incidence and mortality rates of most cancers are increasing in several less developed countries due to adoption of unhealthy lifestyles like smoking, physical inactivity and consumption of caloriedense food.[2] In the 1960s, almost 25\% of global cancer burden was diagnosed in low-income and lower middleincome countries. In 2010, nearly 55\% of the global cancer burden was found in these countries. By 2030, over 9 million cancer patients are assumed to die in developing countries.[1] Based on the increasing trends of cancer patients during the last few decades, the numbers of female cancer patients in

Financial or Other, Competing Interest: None.

Submission 28-07-2016, Peer Review 13-10-2016,

Acceptance 22-10-2016, Published 26-10-2016.

Corresponding Author:

Gurneesh Singh,

Associate Professor,

Department of Obstetrics and Gynaecology,

Maharaja Agrasen Medical College,

Agroha, Hisar.

E-mail: gurneeshellora@yahoo.co.in

DOI: $10.14260 /$ jemds/2016/1447
India have been growing rapidly. Number of female cancer patients in 2004 was 428545 . The number increased in 2009 to 507990.[4] Commonest cancers in female were breast, cervix, ovary, gall bladder, uterus, non-Hodgkin lymphoma, thyroid, etc. with highest incidence above 50 yrs. age. $[5,6,7,8]$

\section{MATERIALS AND METHODS}

In this cross sectional study, histopathologically confirmed all types of female cancer patients from Jan 2014 to May 2016 were included. There were total 118 patients during this study period having different types of cancers. For data of 118 female patients, patients' personal data records were collected from registry book. Data of female specific cancers i.e. breast, cervix, uterus and ovary was analysed in terms of site of cancers and age related distribution. It was compared with National Cancer Registry data from Delhi.

\section{RESULTS}

Although there were different types of cancers found during the study period, data of cancers more common \& specific to females was analysed. Total 118 female cancer patients were found during the study period. Patients having different types of cancers were stratified according to age and site of cancer. Number of breast carcinoma was the highest $(33.05 \%)$, followed by cervix (19.49\%), uterus (7.63\%) and ovary (1.2\%) (Table 1, Fig 1 \& 2). 


\begin{tabular}{|c|c|c|c|c|c|c|}
\hline Age & Cervix & Uterus & Ovary & Breast & Others & Total No. of Cancer Patients \\
\hline$<20$ & 0 & 0 & $1(100 \%)$ & 0 & 0 & $1(0.85 \%)$ \\
\hline $20-30$ & $5(100 \%)$ & 0 & 0 & 0 & 0 & $5(4.24 \%)$ \\
\hline $30-40$ & $3(18.75 \%)$ & $2(12.5 \%)$ & 0 & $8(50 \%)$ & $3(18.75 \%)$ & $16(13.56 \%)$ \\
\hline $40-50$ & $6(22.22 \%)$ & $3(11.11 \%)$ & $3(11.11 \%)$ & $7(25.92 \%)$ & $8(29.62 \%)$ & $27(22.88 \%)$ \\
\hline $50-60$ & $5(16.12 \%)$ & $1(3.23 \%)$ & $1(3.23 \%)$ & $15(48.39 \%)$ & $9(29.03 \%)$ & $31(26.27 \%)$ \\
\hline$>60$ & $4(10.53 \%)$ & $3(7.89 \%)$ & 0 & $9(23.68 \%)$ & $22(57.89 \%)$ & $38(32.20 \%)$ \\
\hline Total & $\mathbf{2 3 ( 1 9 . 4 9 \% )}$ & $\mathbf{9 ( 7 . 6 3 \% )}$ & $\mathbf{5 ( 4 . 2 4 \% )}$ & $\mathbf{3 9}(\mathbf{3 3 . 0 5 \% )}$ & $\mathbf{4 2}(\mathbf{3 5 . 5 9 \% )}$ & $\mathbf{1 1 8}$ \\
\hline \multicolumn{7}{|c|}{ Table I. Types and Age Distribution of Cancers } \\
\hline
\end{tabular}

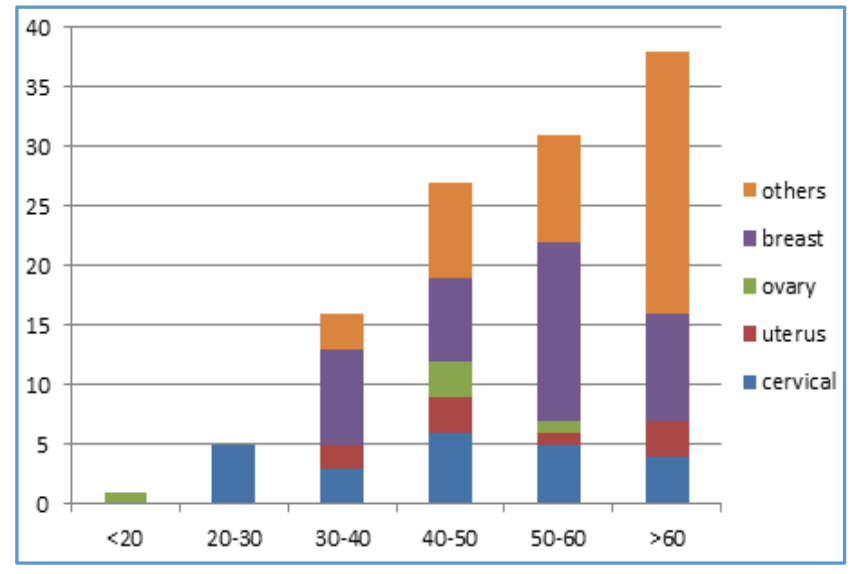

Figure 1. Distribution of Cancers

Highest numbers of patients were in $>60$ years age group (32.20\%), followed by 50-60 yrs. age group (26.27\%) (Table I). In female cancers, breast cancer was commonest (33.05\%), followed by cancer cervix (19.49\%). Maximum no. of breast cancer cases were in 50-60 yrs. group (48.39\%) and cervical cancer in 40-50 yrs. group (22.22\%). Commonest malignancy in women below 20 yrs. was ovarian cancer, in 20-30 yrs. group was cervical cancer and after 30 yrs. was breast cancer.

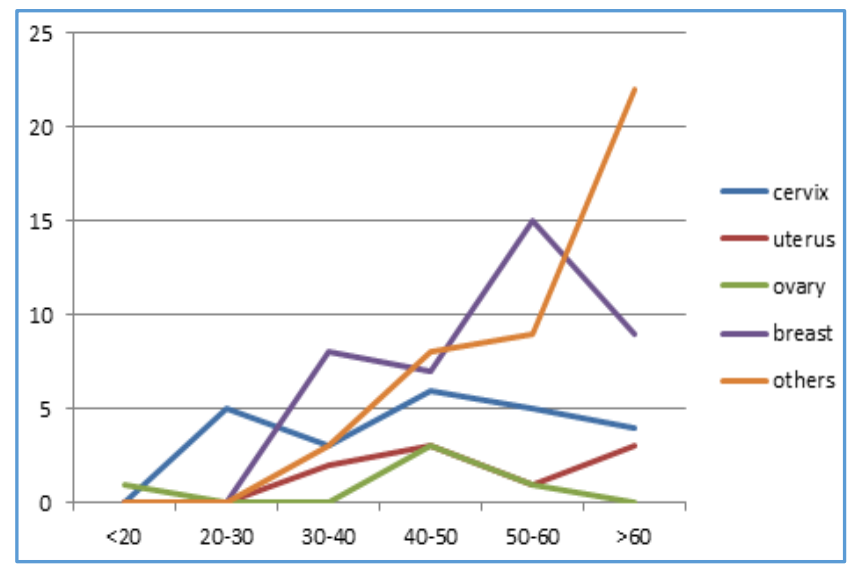

Figure 2. Prevalence of Cancers Age wise

Among all cancers, incidence of breast cancer was highest from 30 yrs. age onwards with peak at 50-60 yrs. age group. Incidence of cervical cancer was second highest with peak at 40-50 yrs. age group. Higher cancer incidence in females was after 60 yrs. age partly due to other types of cancers e.g. oral cancer, colon cancer, non-Hodgkin lymphoma, thyroid cancer, lung cancer, urinary bladder cancer, etc.

\begin{tabular}{|c|c|c|c|c|}
\hline $\begin{array}{c}\text { Site of } \\
\text { Cancer }\end{array}$ & $\begin{array}{c}\text { Mamc } \\
(\mathbf{2 0 1 4 - 1 6 )}\end{array}$ & $\begin{array}{c}\text { Delhi } \\
(\mathbf{1 9 9 0 - 9 6 )}\end{array}$ & $\begin{array}{c}\text { Delhi } \\
\mathbf{( 2 0 0 1 - 0 3 )}\end{array}$ & $\begin{array}{c}\text { Delhi } \\
\mathbf{2 0 1 2}\end{array}$ \\
\hline Breast & 39 & 5511 & 3777 & 2744 \\
$(33.05 \%)$ & $(21.31 \%)$ & $(25.11 \%)$ & $(28.59 \%)$ \\
\hline Cervix & 23 & 5153 & 2241 & 1039 \\
$(19.49 \%)$ & $(19.93 \%)$ & $(14.90 \%)$ & $(10.83 \%)$ \\
\hline Uterus & 9 & 151 & 574 & 366 \\
$(7.63 \%)$ & $(0.58 \%)$ & $(3.82 \%)$ & $(3.81 \%)$ \\
\hline Ovary & 5 & 1636 & 1081 & 688 \\
$(6.33 \%)$ & $(7.19 \%)$ & $(7.17 \%)$ \\
\hline $\begin{array}{c}\text { Total no. of } \\
\text { women with } \\
\text { cancers }\end{array}$ & 118 & 25861 & 15044 & 9598 \\
\hline Table 2. Comparison with Cancer trends Delhi Population \\
\multicolumn{5}{|c|}{ Cancer based Registry } \\
\hline
\end{tabular}

On comparing with National population based Cancer Registry, Delhi, incidence of breast cancer, cervix, uterus was higher but incidence of ovarian cancer was low.

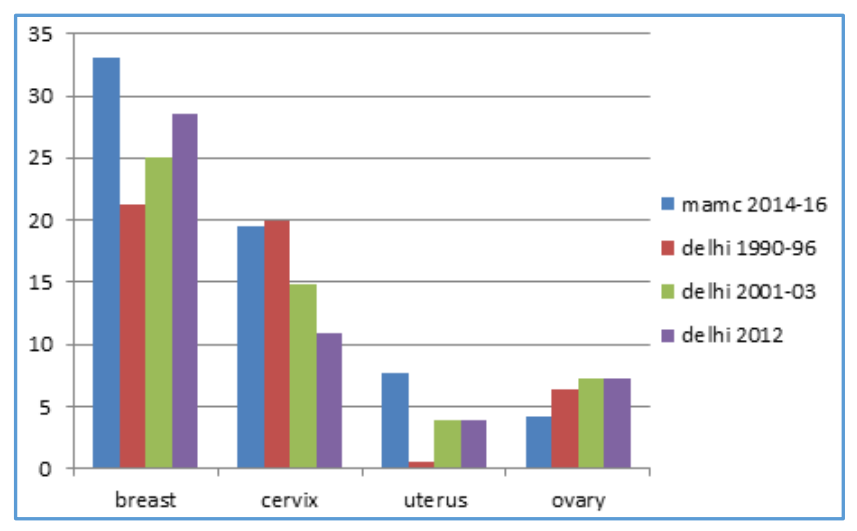

Figure 3. Comparison with Cancer Trends - Delhi Population Cancer Based Registry

\begin{tabular}{|c|c|c|c|c|}
\hline & $\begin{array}{c}\text { MAMC } \\
\text { 2014-16 }\end{array}$ & $\begin{array}{c}\text { Delhi } \\
\mathbf{9 0 - 9 6}\end{array}$ & $\begin{array}{c}\text { Delhi } \\
\mathbf{2 0 0 1 - 0 3}\end{array}$ & $\begin{array}{c}\text { Delhi } \\
\mathbf{2 0 1 2}\end{array}$ \\
\hline Age & Cervix & Cervix & Cervix & Cervix \\
\hline$<20$ & 0 & 0.27 & 0.09 & 0 \\
\hline $20-30$ & 21.74 & 3.36 & 2.16 & 1.64 \\
\hline $30-40$ & 13.04 & 16.84 & 14.02 & 12.05 \\
\hline $40-50$ & 26.09 & 30.10 & 27.58 & 28.16 \\
\hline $50-60$ & 21.74 & 25.87 & 26.24 & 24.69 \\
\hline$>60$ & 17.39 & 23.56 & 29.92 & 33.46 \\
\hline Table 3. Percentage Distribution of Cancers in Females, \\
\multicolumn{5}{|c|}{ Carcinoma Cervix } \\
\hline
\end{tabular}




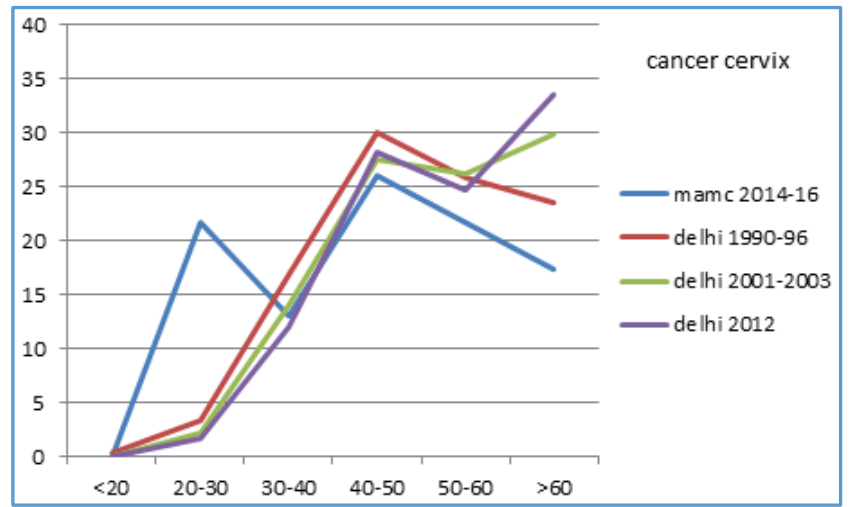

Figure 4. Percentage Distribution of Cancers in Females, Carcinoma Cervix

Incidence of cancer cervix was highest in 40-50 yrs. age group, as compared to National Cancer Registry Delhi data having highest incidence above $60 \mathrm{yrs}$. of age.

\begin{tabular}{|c|c|c|c|c|}
\hline & $\begin{array}{c}\text { MAMC } \\
\mathbf{2 0 1 4 - 1 6}\end{array}$ & $\begin{array}{c}\text { Delhi } \\
\mathbf{9 0 - 9 6}\end{array}$ & $\begin{array}{c}\text { Delhi } \\
\mathbf{2 0 0 1 - 0 3}\end{array}$ & $\begin{array}{c}\text { Delhi } \\
\mathbf{2 0 1 2}\end{array}$ \\
\hline Age & Uterus & Uterus & Uterus & Uterus \\
\hline$<20$ & 0 & 0.75 & 0 & 0 \\
\hline $20-30$ & 0 & 3.61 & 2.49 & 0 \\
\hline $30-40$ & 22.22 & 8.42 & 6.04 & 5.51 \\
\hline $40-50$ & 33.33 & 22.11 & 18.12 & 15.70 \\
\hline $50-60$ & 11.11 & 27.82 & 32.68 & 31.68 \\
\hline$>60$ & 33.33 & 37.29 & 40.67 & 47.11 \\
\hline Table 4. Percentage Distribution of Cancers in Females, \\
Carcinoma Uterus \\
\hline
\end{tabular}

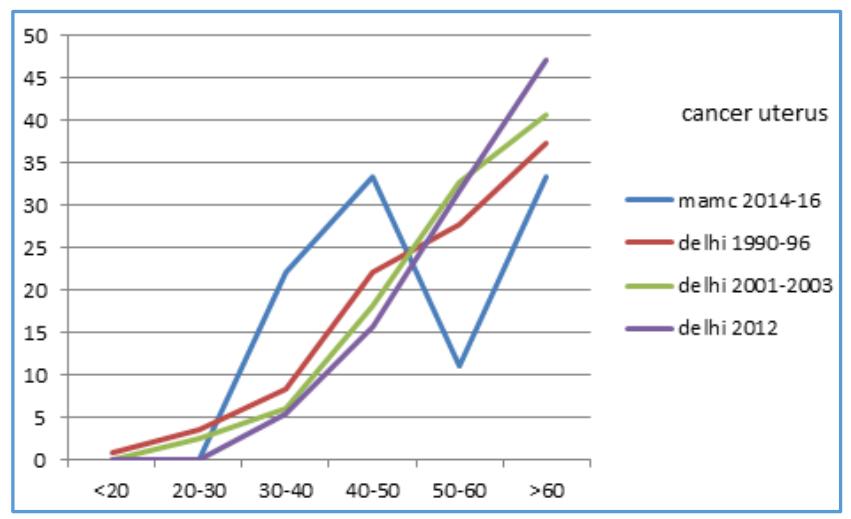

Figure 5. Percentage Distribution of Cancers in Females, Carcinoma Uterus

Incidence of cancer uterus was highest in 40-50 yrs. age group and $>60$ yrs. group whereas it was highest in $>60$ yrs. group in National Cancer Registry, Delhi.

\begin{tabular}{|c|c|c|c|c|}
\hline & $\begin{array}{c}\text { MAMC } \\
\text { 2014-16 }\end{array}$ & $\begin{array}{c}\text { Delhi } \\
\mathbf{9 0 - 9 6}\end{array}$ & $\begin{array}{c}\text { Delhi } \\
\mathbf{2 0 0 1 - 0 3}\end{array}$ & $\begin{array}{c}\text { Delhi } \\
\mathbf{2 0 1 2}\end{array}$ \\
\hline Age & Ovary & Ovary & Ovary & Ovary \\
\hline$<20$ & 20 & 3.97 & 3.75 & 4.52 \\
\hline $20-30$ & 0 & 8.07 & 7.50 & 7.87 \\
\hline $30-40$ & 0 & 13.75 & 13.03 & 10.50 \\
\hline $40-50$ & 60 & 25.86 & 27.27 & 24.05 \\
\hline $50-60$ & 20 & 24.82 & 23.90 & 22.30 \\
\hline$>60$ & 0 & 23.53 & 24.55 & 30.76 \\
\hline Table 5. Percentage Distribution of Cancers in Females, \\
Carcinoma Ovary \\
\hline
\end{tabular}

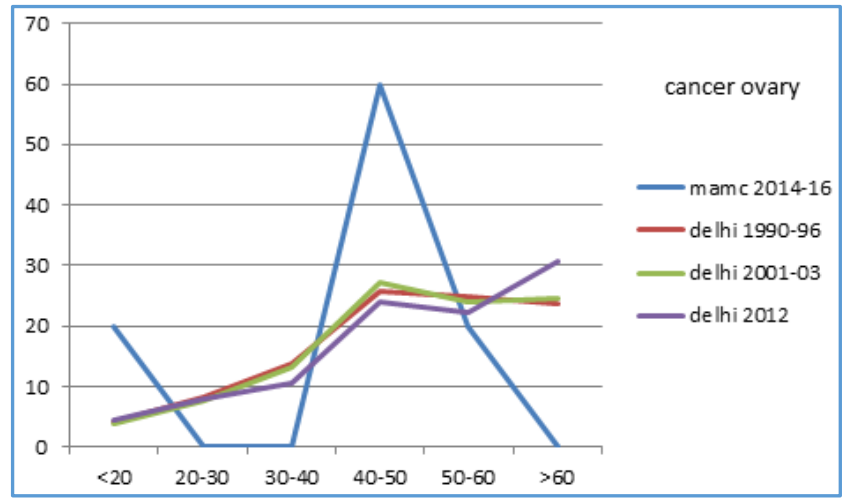

Figure 6. Percentage Distribution of Cancers in Females, Carcinoma Ovary

Incidence of ovarian cancer was found highest between 40-50 yrs. group as compared to National Cancer Registry, Delhi where it was highest in 40-50 yrs. group in 90-96 and 2001-03 data, but highest in $>60$ yrs. group in 2012 data.

\begin{tabular}{|c|c|c|c|c|}
\hline & $\begin{array}{c}\text { MAMC } \\
\mathbf{2 0 1 4 - 1 6}\end{array}$ & $\begin{array}{c}\text { Delhi } \\
\mathbf{9 0 - 9 6}\end{array}$ & $\begin{array}{c}\text { Delhi } \\
\mathbf{2 0 0 1 - 0 3}\end{array}$ & $\begin{array}{c}\text { Delhi } \\
\mathbf{2 0 1 2}\end{array}$ \\
\hline Age & Breast & Breast & Breast & Breast \\
\hline$<20$ & 0 & 0.49 & 0.11 & 0 \\
\hline $20-30$ & 0 & 3.92 & 3.60 & 2.45 \\
\hline $30-40$ & 20.51 & 18.02 & 13.32 & 12.35 \\
\hline $40-50$ & 17.95 & 28.60 & 28.58 & 25.73 \\
\hline $50-60$ & 38.46 & 26.53 & 27.44 & 27.41 \\
\hline$>60$ & 23.08 & 22.45 & 26.96 & 32.05 \\
\hline Table 6. Percentage Distribution of Cancers in Females, \\
Carcinoma Breast \\
\hline
\end{tabular}

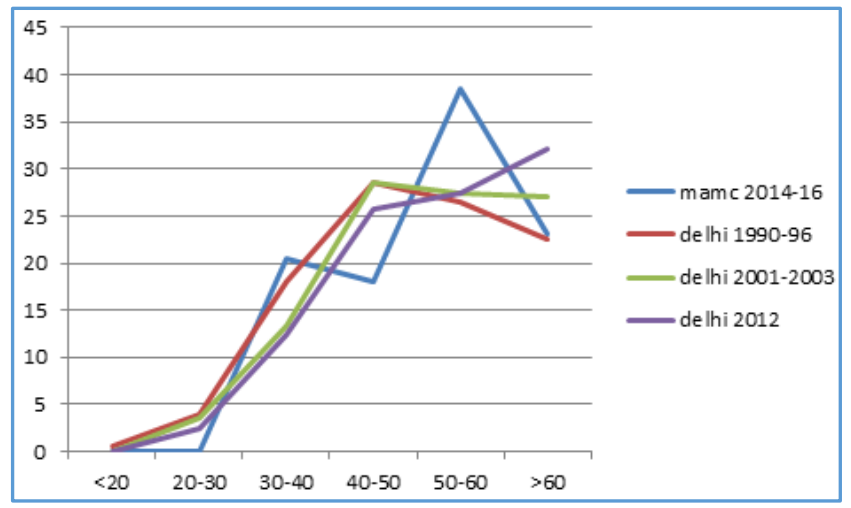

Figure 7. Percentage Distribution of Cancers in Females, Carcinoma Breast

Incidence of breast cancer was found highest between 50 60 yrs. age group, as compared to National Cancer Registry, Delhi where it was highest in 40-50 yrs. group in 90-96 and 2001-03 data, but highest in $>60$ yrs. group in 2012 data.

\section{DISCUSSION}

Frequency of different types of cancer occurring in Indian female population is not similar with that of other population groups worldwide. Ethnicity, genetic predisposition, life style, socio-economic condition, environmental pollution and many other risk factors interplay for the different distribution which is also evident in a number of other study findings.

In this study, number of breast carcinoma was the highest followed by cervix, uterus and ovary. 
Worldwide, cervical cancer is considered to be the second commonest cancer in women as far as mortality and incidence is concerned and India contributes to about 20$30 \%$ of the global burden. Cervical cancer constituted $28.8 \%$ of the cancers in women and $73.3 \%$ of all gynaecological cancers. Cervical cancer in rural women rose 2.91 fold from block yrs. 1983-87 to block yrs. 2003-2007.[9] However, in our study, cervical cancer contributed $19.49 \%$ of all cancers of females. More than half (60\%) cases were between 20-50 yrs. age as compared to National Cancer Registry, Delhi 2012 having 58\% cases after 50 yrs. of age. Rise in cervical cancer at an earlier age can be attributed to rise in early sexual activity, many sex partners, rise in sexually transmitted diseases including Human Papilloma Virus, smoking, etc. In National Registry, Delhi, the incidence of cervical cancer has fallen from 1990-96 [CR (crude ratio) 17.4, AAR (age adjusted ratio) 26.6] to 2012 [CR 13.2, AAR 15.53]. This fall may be due to increased awareness, early screening and detection due to increased women literacy, better and affordable health facilities over last three decades.

Rise in the risk factors of uterine cancer i.e. early menarche, increased longevity, nulliparity, obesity, hormonal treatment for breast cancer have led to rise in uterine cancer from 1990-96 (National Cancer Registry, Delhi CR 2.3 AAR 3.9) to 2012 (National Cancer Registry, Delhi CR 4.7 AAR 5.98). Relative percentage of cancer rate in our study (7.63\%) is higher than National Cancer Registry data, Delhi 2012 (3.81\%).

Risk factors of ovarian cancer: Oestrogen hormone replacement therapy, early menarche, nulliparity, smoking, polycystic ovarian disease; all have risen leading to increase in incidence of ovarian cancer as seen in National Cancer Registry, Delhi 1990-96 (CR 5.5 AAR 8.3) to 2012 (CR 8.7 AAR 10.02). However, in our study, relative percentage of ovarian cancer was found low $4.24 \%$ as compared to National Cancer Registry, Delhi 2012 (7.17\%).

Risk factors of breast cancer[10]: Higher education, higher family income, non-veg diet, delayed marriage, delayed child birth, nulliparity, $<2$ children, obesity, early menarche, postmenopausal hormones therapy, alcohol intake, etc. all have increased during last decade. Along with increase in availability of advanced medical treatment, this has led to early detection and management of breast cancers. In this study, highest incidence of breast cancer was in 50-60 yrs., and National Cancer Registry data, Delhi reflects these trends, showing increase in no. of total breast cancer patients and their increased survival beyond 60 yrs. age.

In Indian subcontinent, carcinomas of breast and cervix are the commonest malignancies in females. Carcinoma cervix is less common in western population.[1] In USA (2012), lung cancer followed by breast cancer has the highest incidences and mortality rates amongst females.[11] In this study, the subjects were also categorised on the basis of age groups. It was observed that the highest number (32.2\%) of cancer patients were in $>60$ years age group, followed by $26.27 \%$ in $50-60$ years age group. Similar pattern was observed in National Cancer Registry, Delhi, reports (1990$96,2001-03,2012)$ that maximum number of the cancer patients were in age group $>60$ yrs. $(28.24 \%, 31.26 \%, 35.58$ $\%$ ) followed by 50-60 yrs. age group (24.28\%, 23.90\%, 23.94\%). Most frequent cancer in females was breast cancer followed by carcinoma cervix, similar to our study.

\section{CONCLUSION}

The findings of the study show that breast cancer, cervical cancer, uterine cancer are more prevalent in rural areas of Haryana than Delhi and manifest early in younger age.

\section{REFERENCES}

1. Uddin AK, Khan ZJ, Islam J, et al. Cancer care scenario in Bangladesh. South Asian J Cancer 2013;2(2):102-4.

2. Jemal A, Center MM, DeSantis C, et al. Global patterns of cancer incidence and mortality rates and trends. Cancer Epidemiol Biomarkers Prev 2010;19(8):1893-907.

3. Globocon 2012, Estimated cancer incidence, mortality and prevalence, worldwide in 2012. International agency for work on cancer, WHO, 2012.

4. Ali I, Waseem AW, Saleem K. Cancer scenario in India with future perspectives. Cancer Therapy 2011;8:56-70.

5. Nandakumar A. Consolidated Report of the population based cancer registries: 1990-96 supplement: year-wise tabulation of incident cancers and rates by site and gender. National cancer registry programme, Indian council of medical research. Available from: http://www.ncrpindia.org/Old_Reports/PBCR_Supplime nt/supplement_pbcr.pdf

6. Gupta BD. Hospital based cancer registry; post graduate institute of medical education \& research, Chandigarh. individual registry data: 1984-1993. Indian Council of Medical Research. Available from: http://www.icmr.nic.in/ncrp/ncrp_h/chandigarh.pdf

7. Raina V, Tyagi BB, Manoharan N. Population based cancer registry, Delhi Dr. B.R. Ambedkar Institute Rotary Cancer Hospital, All India Institute of Medical Sciences, New Delhi. Individual Registry Data: 2001-2003. Indian Council of Medical Research. Available from: http://www.icmr.nic.in/ncrp/report_pop_200104/05_Delhi\%20Pages\%20154-173.pdf

8. Swaminathan S. Three-year report of population based cancer registries 2012-2014. National centre for disease informatics and research, national cancer registry programme, Indian Council of Medical Research. Available from:

http://ncrpindia.org/ALL_NCRP_REPORTS/PBCR_REPOR T_2012_2014/ALL_CONTENT/Annexure/Delhi_Ann.pdf

9. Chhabra S, Bhavani M, Mahajan N, et al. Cervical cancer in Indian rural women: trends over two decades. J Obstet Gynaecol 2010;30(7):725-8.

10. Kamath R, Mahajan KS, Ashok L, et al. A study on risk factors of breast cancer among patients attending the tertiary care hospital, in Udupi District. Indian J Community Med 2013;38(2):95-9.

11. American Cancer Society. Cancer Facts \& Figures 2013. Atlanta: American Cancer Society; 2013. Available from: http://www.cancer.org/acs/groups/content/@epidemiol ogysurveilance/documents/document/acspc-036845.pdf 